\title{
Role of Comprehensive Diabetes Care in Known Diabetes Patients from Vidarbha Region
}

\author{
Rohit Sane ${ }^{1}$, Rahul Mandole, , , Gurudatta Anand Amin ${ }^{3}$, Pravin Ghadigaokar ${ }^{3}$, Sneha Paranjape $^{4}$, \\ Komal Vasnik ${ }^{5}$, Sumera Sabir ${ }^{6}$, Rupali Kaware ${ }^{7}$, Rakesh Kukade ${ }^{8}$ \\ ${ }^{1}$ Madhavbaug Cardiac Hospitals and Clinics, Thane, India \\ ${ }^{2}$ Department of Research \& Development, Madhavbaug Cardiac Clinic and Hospital, Thane, India \\ ${ }^{3}$ Madhavbaug Cardiac Clinic and Hospital, Thane, India \\ ${ }^{4}$ Madhavbaug Cardiac Clinic and Hospital, Mumbai, India \\ ${ }^{5}$ Madhavbaug Cardiac Clinic and Hospital, Vidarbha, India \\ ${ }^{6}$ Madhavbaug Cardiac Clinic and Hospital, Dhantoli, Nagpur, India \\ ${ }^{7}$ Madhavbaug Cardiac Clinic and Hospital, Rajpath, Amravati, India \\ ${ }^{8}$ Madhavbaug Cardiac Clinic and Hospital, Mhalgi Nagar, Nagpur, India
}

\section{Email address:}

drrahul@madhavbaug.org (R. Mandole)

${ }^{*}$ Corresponding author

\section{To cite this article:}

Rohit Sane, Rahul Mandole, Gurudatta Anand Amin, Pravin Ghadigaokar, Sneha Paranjape, Komal Vasnik, Sumera Sabir, Rupali Kaware, Rakesh Kukade. Role of Comprehensive Diabetes Care in Known Diabetes Patients from Vidarbha Region. International Journal of Diabetes and Endocrinology. Vol. 5, No. 3, 2020, pp. 41-46. doi: 10.11648/j.ijde.20200503.12

Received: July 13, 2020; Accepted: July 27, 2020; Published: September 3, 2020

\begin{abstract}
Introduction: Number of patients with Diabetes Mellitus (DM) have been doubled in past few decades. India is particularly facing impending massive rise in number of diabetic cases, and therefore India is termed as Diabetes capital of the world by most of the clinicians. Worryingly, prevalence in Vidarbha region in India is rising and its figure as per published literature is $>5 \%$. Comprehensive diabetes care (CDC) is form of Ayurvedic therapy which combines panchkarma techniques and herbal drugs. Aims and objectives: The present study was initiated to evaluate the effectiveness of CDC in patients of DM in terms of glycosylated haemoglobin (HbAlc), body mass index (BMI), oral glucose tolerance test (OGTT), body weight, abdominal girth, etc. in Vidarbha region of India. Materials and methods: The present observational study was conducted across various Madhavbaug clinics in Vidarbha region of India. Data of the patients who were diagnosed with DM i.e. HbA1c $>6.5 \%$ and received CDC therapy of 6 settings over 12 weeks was analysed. Results: In the present study, out of 293 type 2 diabetic patients, 179 were males $(61 \%)$, while 114 were females $(39 \%)$, thus male: female ratio was $1.57: 1$. At the end of 12 weeks of CDC therapy, number of patients with controlled DM (154) was significantly increased as compared to baseline (0), while the HbAlc also reduced from 6.89 at week 12 as compared to 8.45 at baseline, which was statistically significant. Other parameters like BMI, abdominal girth, etc. were significantly improved after 12 weeks of CDC therapy. Conclusion: Given the findings of present study, CDC therapy can be used as efficacious alternative form of therapy in the management of DM.
\end{abstract}

Keywords: Diabetes Mellitus, Comprehensive Diabetes Care, Ayurveda, Panchkarma

\section{Introduction}

Past few decades have witnessed a massive rise in prevalence of non-communicable diseases and hence their contribution to diseased states and fatality. Diabetes mellitus is one of the commonest non-communicable disease falling in this category. It is has been cited that number of patients with DM have been doubled in past few decades [1]. Globally, there are nearly 450 million patients of DM, of which major chunk of patients are found in China and India. India is particularly facing impending massive rise in number of diabetic cases, and therefore India is termed as Diabetes capital of the world by most of the clinicians [1]. Worryingly, 
prevalence in Vidarbha region is rising and its figure as per published literature is $>5 \%$ [2].

Clinically, DM is characterized by clinical triad of polydipsia, polyuria and polyphagia. However, DM is diagnosed definitively by laboratory diagnosis. In this regard, oral glucose tolerance test (OGTT) still remains the commonly employed test to diagnose DM, as it is comparatively cheaper, easily available, fair amount of sensitivity and specificity etc. It consists of fasting blood glucose (FBG) and post meal glucose levels (PMG) Since, $\mathrm{DM}$ is disorder of glucose metabolism, it is vital to know about the glucose control homeostasis over preceding 2-3 months period. This cannot be detected by the conventional OGTT, but can be detected by serum measurement of glycosylated hemoglobin i.e. HbA1c. The diagnostic cutoff levels for diagnosis of DM in FBS, PMG, and $\mathrm{HbA1c}$ are $\geq$ $126 \mathrm{mg} / \mathrm{dl}, 140 \mathrm{mg} / \mathrm{dl}$ and $6.5 \%$, respectively [3].

The persistent hyperglycemia in DM alters the cardiovascular dynamics in the body and it leads to variety of complications like nephropathy, coronary heart disease, vasoocclusive episodes, etc. The major cause of mortality in diabetic patients are renal and cardiac complications. Apart from these, non-fata complications like diabetic foot ulcer, retinopathy, etc. significantly hamper the quality of life of patients and it may also results in disability [4].

Since, DM is chronic disease it cannot be cured completely but it can be managed to keep the derangements to minimum possible limits. It is usually treated by allopathic class of drugs known as oral hypoglycemic drugs (OHDs) along with advice on dietary and lifestyle modifications [5]. These drugs act by reducing the blood glucose levels, and the aim of therapy is to reduce the insulin resistance and hyperglycemia. They act by various mechanisms which vary form increase glucose uptake by tissues, reducing gluconeogenesis, promoting lipolysis thus reducing the insulin resistance [6].

Major drawback of these drugs is increased cost burden of treatment, and more importantly adverse effects which further hamper the quality of life which is already deranged due to the disease. It is due to these factors that patient's compliance to this therapy is less. This has been to be as low as $97 \%$ in one of the clinical study by Alawdi et al. who reported moderate to poor patient adherence to OHDs in these patients [7]. Some of these adverse effects are hypoglycemia, dizziness, fainting, headache, urinary tract infections, anemia of chronic disease, megaloblastic anemia [6].

Despite availability of numerous OHDs and extensive guidelines for management of DM, the prevalence of disease is continually rising raises an alarm to explore for a newer therapeutic alternate for the management of DM. One such potent option is Ayurvedic therapy, which is ancient Indian medical science aiming to treat the disease from its root cause. Ayurvedic physicians administer various herbal drugs, panchkarma, diet therapy depending on the type of disease [8]. Comprehensive Diabetes Care (CDC) is one such therapy which combines Panchkarma, herbal drugs usage and diet therapy.
Panchakarma is an internal detoxification process, which involves 3 key procedures under the umbrella of CDC therapy- Snehana i.e. centripetal oleation, Swedana i.e. passive heat therapy, Basti i.e. per rectal herbal drug administration [9]. However, clinical data on effectiveness of CDC in patients of DM in Vidarbha region is scarce. Therefore, we planned the present study to evaluate the effectiveness of CDC in patients of DM in terms of HbAlc, BMI, OGTT, body weight, abdominal girth, etc.

\section{Subjects and Methods}

\subsection{Study Design}

Retrospective record based study.

\subsection{Study Site}

Madhavbaug clinics across Vidarbha region of Maharashtra state.

\subsection{Study Period}

July 2017 to January 2018.

\subsection{Study Participants}

Patients suffering from type 2 DM (HbAlc $>6.5 \%)$ [5], of either sex who attended Madhavbaug clinics across Vidarbha region of Maharashtra.

\subsection{Methodology}

The data of patients who had been administered CDC with minimum 6 sittings over a span of 12 weeks were considered for the study, out of which 4 sittings were done in $1^{\text {st }}$ month, and 1 sitting per month for next 2 months. These patients were maintained on diet plan of 800-1000 calories intake per day, according to patient medical records. The diet plan consisted of low carbohydrates, moderate proteins, and low fats. Cases were identified, and data was assessed from the records of Madhavbaug clinics in Maharashtra. The selection was based upon the availability of complete relevant baseline data (day 1 of CDC) and final day data (day 90 of CDC) of the patients. The information about prescribed concomitant medicines, if any, was also noted down. The CDC is a 3-step procedure which was performed on the patients of type $2 \mathrm{DM}$ after a light breakfast. One sitting of the procedure took 65 75 minutes, as described in table 1 [10].

\subsection{Patient Categorization Post CDC Therapy}

Controlled- HbA1c $<5.7$.

Borderline- HbA1c 5.7-6.5.

Uncontrolled- HbAlc $>6.5$.

\subsection{Diet Box}

Diet box was given to the patients, which was 1 month food packing designed to comply with low carbohydrate and low fat diet with daily calorie intake of 800 calories. 1 diet 
box was designed for 1 month, therefore number of diet

compliance diet.

boxes were equivalent to number of months on taking the

Table 1. Study Treatment: Comprehensive Diabetes Care (CDC).

\begin{tabular}{|c|c|c|c|}
\hline Step of CDC & Type of Therapy & Herbs used for therapy & Duration of Therapy \\
\hline Snehana & $\begin{array}{l}\text { Massage or external oleation (centripetal upper } \\
\text { strokes on the body) }\end{array}$ & $\begin{array}{l}100 \mathrm{ml} \text { Azadirechta indica (neem) extract processed } \\
\text { in sesame oil }\end{array}$ & 20 minutes \\
\hline Swedana & Passive heat therapy to the body & $\begin{array}{l}\text { Dashmoola (group of ten herbal roots) with steam at } \\
<40 \text { degrees Celsius) }\end{array}$ & $\begin{array}{l}15-20 \text { minutes }+3-4 \text { minutes } \\
\text { of relaxation after procedure }\end{array}$ \\
\hline Basti kadha & $\begin{array}{l}\text { Per-rectal drug administration should be in } \\
\text { body for }>15 \text { minutes for maximum absorption }\end{array}$ & $\begin{array}{l}\text { Mixture of } 40 \% \text { Gudmaar (Gymnema sylvestre), } 20 \% \\
\text { Daruharidra (Berberis aristate) and } 40 \% \\
\text { Yashtimadhu (Glycyrrhiza glabra) }\end{array}$ & 10 minutes \\
\hline
\end{tabular}

\subsection{Statistical Analysis}

Data were pooled and coded in Microsoft Excel spreadsheet. R Version 3.4.1 software was used to analyse the data. Categorical data were represented in the frequency form and continuous data were presented as the Mean \pm SD. Paired t-test was used to assess the difference between baseline values and $90^{\text {th }}$ day after treatment. Histogram were used to represent the graphs.

Patient record data selection for the present study is depicted in figure 1.

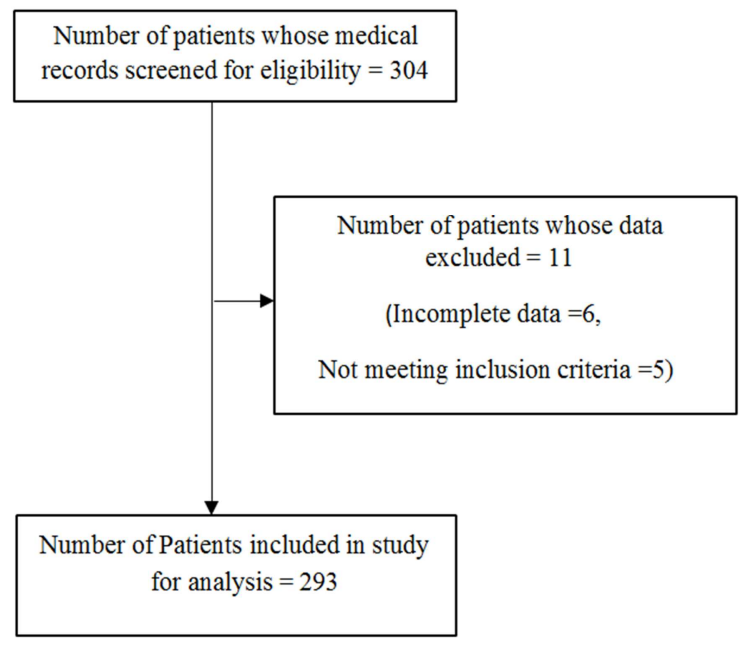

Figure 1. Patient record selection for the present study.

\section{Results}

In the present study, out of 293 type 2 diabetic patients, 179 were males $(61 \%)$, while 114 were females $(39 \%)$, thus male: female ratio was 1.57:1 [figure 1].
$18 \%$ of the total patients were not given any diet boxes, while 1 diet box was given to $22 \%, 2$ diet boxes to $23 \%, 3$ diet boxes to $36 \%$ and 4 diet boxes were given to $1 \%$ of the patients [Figure 2].

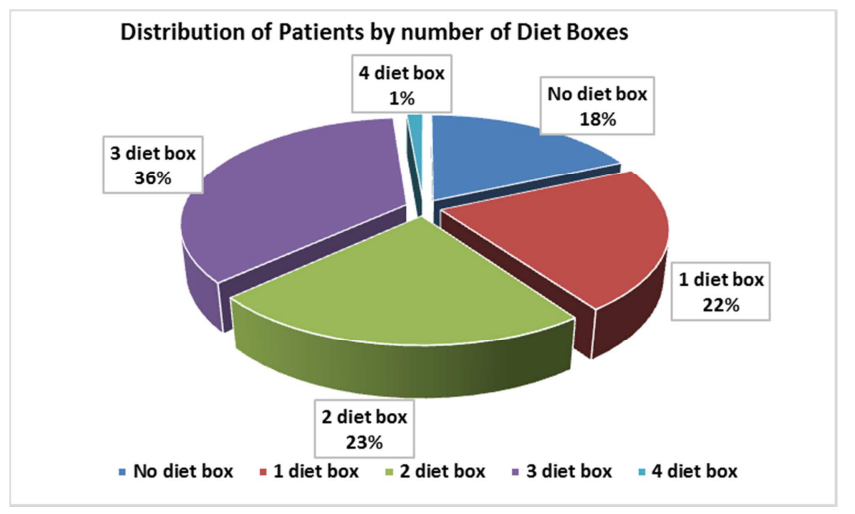

Figure 2. Number of diet boxes used by patients of present study.

On analysing the anthropometric parameters in the patients of present study, it was found that body mass index (BMI) was reduced from $27.88 \pm 0.98 \mathrm{~kg} / \mathrm{m}^{2}$ at baseline to $26.10 \pm 1.1$ $\mathrm{kg} / \mathrm{m}^{2}$ at the end of 12 weeks of CDC therapy, and this difference was statistically significant $[p=0.05]$. Similarly abdominal girth was reduced from $97.47 \pm 4.6$ at baseline to $92.81 \pm 3.8$ at 12 weeks of CDC therapy [p=0.05]. Similarly cardiopulmonary parameters like systolic blood pressure (SBP), diastolic BP (DBP), VO2 peak showed improvements in reading at 12 weeks of CDC therapy, as compared to baseline and these differences were highly statistically significant. Lipid parameters showed similar trends which can be seen in table 2 .

Table 2. Anthropometric, cardio-pulmonary and lipid parameters in the patients of present study at baseline and 12 weeks of CDC therapy.

\begin{tabular}{llllll}
\hline Sr. No. & Parameter & Measurement & Baseline & 12 week & p-value \\
\hline \multirow{3}{*}{1} & Weight & $71.48 \pm 3.1$ & $67.12 \pm 3.3$ & 0.05 \\
& \multirow{3}{*}{ Anthropometry } & BMI & $27.88 \pm 0.98$ & $26.10 \pm 1.1$ & 0.05 \\
2 & ABG & $97.47 \pm 4.6$ & $92.81 \pm 3.8$ & 0.05 \\
& & SBP & $131.07 \pm 4.7$ & $124.25 \pm 6.22$ & 0.02 \\
& \multirow{3}{*}{ Cardio-pulmonary } & DBP & $80.39 \pm 2.9$ & $76.42 \pm 3.4$ & 0.07 \\
& & VO2 peak & $16.68 \pm 1.1$ & $26.15 \pm 2.2$ & 0.001 \\
& & Cholesterol & $128.5 \pm 3.96$ & $90.83 \pm 5.01$ & 0.020 \\
& \multirow{3}{*}{ Lipid profile } & HDL & $32.09 \pm 1.4$ & $39.0 \pm 2.34$ & 0.01 \\
& & LDL & $79.1 \pm 4.1$ & $52.09 \pm 5.1$ & 0.001 \\
\hline
\end{tabular}


BMI- Body Mass Index, ABG-abdominal girth, SBPsystolic blood pressure, DBP-diastolic blood pressure, HDLHigh Density Lipoprotein, LDL- Low Density Lipoprotein, TG-Triglycerides.

On analysing the results of $\mathrm{HbA1c}$ values in patients who have completed 12 weeks of CDC therapy, it was found that normal $\mathrm{HbAlc}$ was seen in 154 patients $(52 \%)$, borderline $\mathrm{HbAlc}$ was seen in 61 patients $(18 \%)$ as compared to 131 patients $(48 \%)$ at baseline, while abnormal $\mathrm{HbAlc}$ readings were noted in 78 patients $(30 \%)$ as compared to 162 patients $(55 \%)$ at baseline [figure 3].

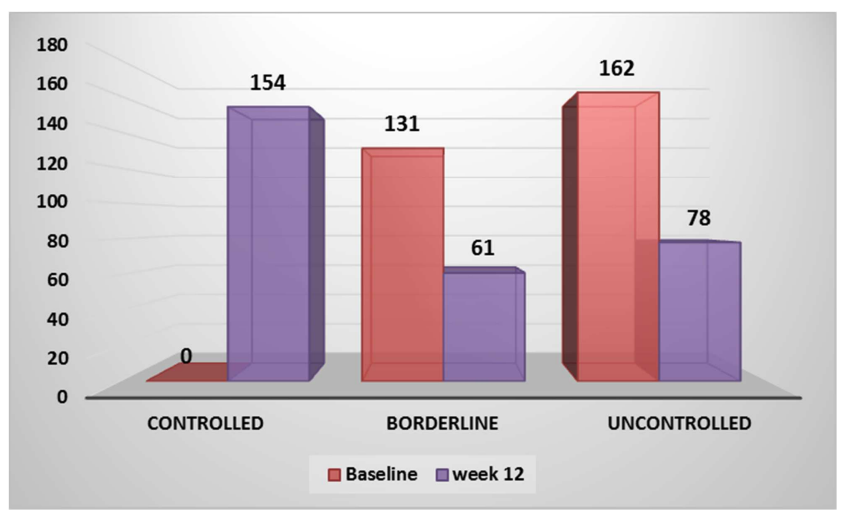

Figure 3. Results of HbAlc in patients who had completed 12 weeks of CDC therapy.

Glycosylated hemoglobin $(\mathrm{HbAlc})$ reduced from 8.45 at baseline to 6.89 at week 12 of completion of CDC therapy, and the difference was statistically significant [figure 4].

Medication history was available in 293 patients, out of which majority of the patients were taking biguanide and sulfonylureas (SU). The number of tablets/patient ratio reduced from 1.04 at baseline to 0.39 at week 12 of CDC therapy, thus there was $62 \%$ reduction in number patients taking allopathic medications after 12 weeks of CDC therapy, with major reduction seen in intake of biguanides and SU [table 3].

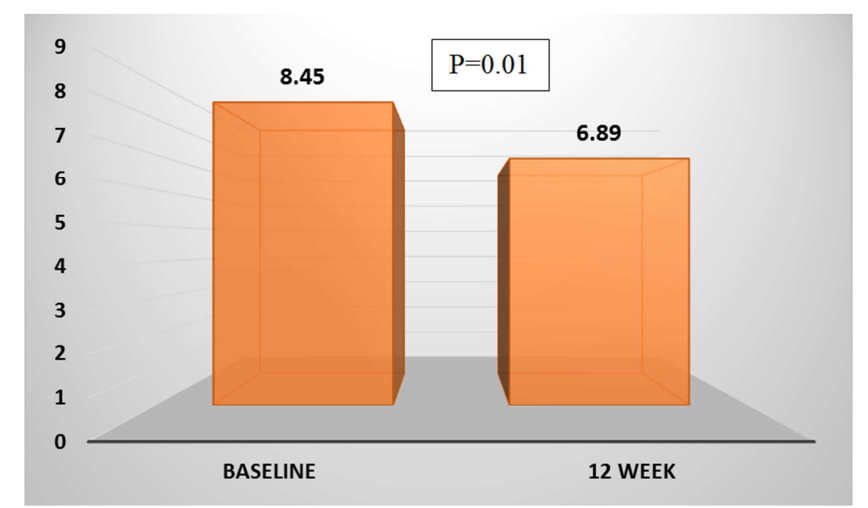

Figure 4. Glycosylated haemoglobin (HbAlc) in patients of present study at baseline and at 12 weeks of taking $C D C$ therapy.

Table 3. Consumption of allopathic medications by the patients in the present study at baseline and at 12 weeks of CDC therapy.

\begin{tabular}{lllll}
\hline \multicolumn{4}{l}{ No. of patients taking allopathic medicines } \\
\hline Sr. No. & Medication & Baseline & Week 12 & p-value \\
\hline 1 & $\beta$ blocker & 22 & 12 & 0.001 \\
2 & ARB & 42 & 25 & 0.001 \\
3 & CCB & 34 & 15 & 0.001 \\
4 & Diuretic & 8 & 3 & 0.05 \\
5 & SU & 70 & 37 & 0.001 \\
6 & Biguanide & 81 & 17 & 0.001 \\
7 & Antiplatelet & 12 & 3 & 0.001 \\
8 & DPP4 inhibitor & 18 & 2 & 0.001 \\
9 & Statins & 18 & 1 & 0.001 \\
10 & Tablet/patient ratio & 1.04 & 0.39 & 0.001 \\
\hline
\end{tabular}

ARB-angiotensin receptor blocker, CCB-calcium channel blocker, SUsulfonylurea, DPP4- dipeptidyl peptidase.

On analyzing $\mathrm{HbA} 1 \mathrm{c}$ status at end of week 12 of CDC therapy, it was found that number of patients with controlled DM status increased and that with uncontrolled status reduced at week 12. The greatest changes were observed in patients with duration of $\mathrm{DM}>10$ years. [table 4].

Table 4. HbAlc results and duration of DM.

\begin{tabular}{|c|c|c|c|c|c|}
\hline \multirow{2}{*}{ Duration of DM } & \multirow{2}{*}{ Period of CDC therapy } & \multicolumn{3}{|c|}{ HbA1c status } & \multirow{2}{*}{$\mathbf{N}$} \\
\hline & & Controlled & Borderline & Uncontrolled & \\
\hline \multirow{2}{*}{$<2 \mathrm{yrs}$} & Baseline & 0 & 24 & 28 & 52 \\
\hline & week 12 & 27 & 12 & 13 & 52 \\
\hline \multirow{2}{*}{$2-10 \mathrm{yrs}$} & Baseline & 0 & 39 & 52 & 91 \\
\hline & week 12 & 44 & 21 & 26 & 91 \\
\hline \multirow{2}{*}{$>10 \mathrm{yrs}$} & Baseline & 0 & 68 & 82 & 150 \\
\hline & week 12 & 83 & 28 & 39 & 150 \\
\hline
\end{tabular}

\section{Discussion}

Ayurvedic physicians have been treating DM since ages using Panchkarma procedures and administration of herbal drugs, along with dietary modifications. The antihyperglycaemic effects of these therapeutic modality might help to optimize the blood sugar levels in these patients.
Comprehensive diabetes care (CDC) is a type of Ayurvedic therapy intended to manage DM, and it involves use of Panchkarma, herbal drugs administration. Panchkarma is a detoxification process, whose cleansing properties have been proven in literature [9]. There are 3 Panchkarma techniques that are used in CDC- Oleation therapy i.e. Snehana, steam therapy i.e. Swedana, and rectally administered herbal drug therapy i.e. Basti. All these procedures acts by reducing 
glucose production in the liver by inhibit the process of gluconeogenesis, reduction in wear and tear of vascular endothelium, optimization of deranged lipid levels, etc [10].

In the present study, CDC significantly reduced all the important parameters like $\mathrm{HbAlc}$, BMI, etc. Most important of all these parameters is $\mathrm{HbAlc}$, as it is the only diagnostic parameter amongst the available tests to indicate long term glycaemic control over 2-3 months. It is also an independent prognostic indicator in patient of DM. Persistently elevated $\mathrm{HbA1c}$ levels is associated with increased complications and thus the elevated morbidity and mortality rates [11]. From the findings of the present study, CDC can be expected to improve the prognosis, given the significant reduction in $\mathrm{HbAlc}$ at the end of therapy.

However, ACCORD trial results does not favour intense reduction of $\mathrm{HbAlc}$ in management of DM. This multicentric trial was conducted to evaluate the effect of intense HbA1c reduction therapy with the help of multiple antidiabetic drugs as compared to standard regime with less number of antidiabetic drugs on cardiovascular outcomes, with special focus on persistent hyperglycaemia, dyslipidaemia and hypertension. The group with intense reduction in $\mathrm{HbA1c}$ showed increase in cardiovascular events by 3.5 times as compared to standard therapy. Thus, dependency on standard therapy should be least [12-14]. In the present study dependency on standard allopathic drugs reduced significantly at the end of study period, which indicates that this might have a better cardiovascular outcome.

It is well known fact that central obesity, as indicated by increased BMI, abdominal girth, body weight is associated with increased risk of complications in patients with DM [15]. Thus, reduction in these parameters are one of the targets for any antidiabetic regimen. It can inferred from the findings of the present study that CDC will help to reduce the risk of complications in patients of DM, as BMI, abdominal girth, body weight were reduced significantly at the end of CDC therapy.

Snehana is one of the major Panchkarma technique which was used in the present study. It relieves the sympathetic stress of the patient and thus the intrinsic gluconeogenesis, which is under the control of sympathetic nervous system is reduced. It is done with help of Azadirachta indica oil, which has natural anti-infective properties and might help to counteract the dermatological infections in diabetic patients [16]. Swedana exposes the diabetic patients to high temperature of 40-42 degree Celsius through steam. Such passive heat therapy is postulated to sooth the patient and induce sweating, which get rid of excess of sodium and water load in diabetic patients, which maintains the vascular health and thus reducing the chances of vascular complications [10]. Basti is per rectal administration of herbal drugs like $40 \%$ Gudmaar (Gymnema sylvestre), 20\% Daruharidra (Berberis aristate) and $40 \%$ Yashtimadhu (Glycyrrhiza glabra). These drugs are known to stimulate insulin release by stimulating the production of islets of Langerhans and beta cells in the pancreas [10].

Insulin resistance is one of the major pathogenic factor in type 2 DM. Sedentary lifestyle and faulty dietary habits have been cited as the major causes for these insulin resistance. Especially canned foods, junk foods have high amount of calories which are deleterious to already compromised glucose handling mechanism in diabetic patients. Therefore, while explaining the management to the diabetic patients, diet with low carbohydrates and fats with moderate amount of protein is advised to induce and maintain negative calories balance, which is known to improve glucose handling mechanics of the body, and thus reduce the insulin resistance [17].

Dependency on allopathic medications was also reduced in the present study at the end of study period. This will help to reduce the cost burden of the patients, as well reduction in adverse effects associated with the use of allopathic drugs.

\section{Conclusion}

From the findings of the present study, antidiabetic actions of $\mathrm{CDC}$ in the form of reduction in $\mathrm{HbA} \mathrm{c}$, BMI, abdominal girth, etc. have shown effective readings. This was corroborated by more number of patients with controlled diabetic status at the end of therapy. Given the current scenario of rise in number for diabetic patients and their poor compliance to long term use of conventional antidiabetic drugs, CDC can serve as a potent therapeutic alternative in management of DM which will help to overcome these issues.

\section{Source of Funding}

Not applicable.

\section{Conflicts of Interest}

The authors declare that they have no competing interests.

\section{References}

[1] Saeedi P, Petersohn I, Salpea P, Malanda B, Karuranga S, Unwin N, et al. Global and regional diabetes prevalence estimates for 2019 and projections for 2030 and 2045: Results from the International Diabetes Federation Diabetes Atlas, $9^{\text {th }}$ edition. Diabetes Res Clin Pract. 2019 Nov; 157: 107843.

[2] Mohan V, Pradeepa R. Epidemiology of diabetes in different regions of India. Health Administrator 2009; XXII $(1,2)$ : 118 .

[3] American Diabetes Association: Diagnosis and Classification of Diabetes Mellitus. Diabetes Care. 2010 Jan; 33 (Suppl 1): S62-S69.

[4] Forbes JM, Cooper ME. Mechanisms of Diabetic Complications. Physiol Rev. 2013; 93: 137-188.

[5] Madhu S, Srivastava S. Diabetes Mellitus: Diagnosis and Management Guidelines. JIMSA 2015; 28 (1): 47-50.

[6] Piero N, Murugi N, Mwiti K, et al. Pharmacological Management of Diabetes Mellitus. Asian Journal of Biochemical and Pharmaceutical Research 2012; 2 (2): 375380 . 
[7] Alawdi S. Effect of Medication Adherence to Oral Hypoglycemic Drugs on Glycemic Control in Type 2 Diabetic Patients: a Cross Sectional Study. Saudi J Med Pharm Sci. 2019; 5 (6): 543-547.

[8] Dwivedi C, Daspaul S. Antidiabetic Herbal Drugs and Polyherbal Formulation Used For Diabetes: A Review. The Journal of Phytopharmacology 2013; 2 (3): 44-51.

[9] Srikanth N, Haripriya N, Singh R, et al. Diabetes mellitus (madhumeha) and ayurvedic management: an evidence based approach. World Journal of Pharmacy and Pharmaceutical Sciences 2015; 4 (8): 881-892.

[10] Sane R, Ghadigaonkar P, Chaure R, Jain S, Wahane S, Nadapude A, et al. Efficacy of Comprehensive Diabetes Care (CDC) Management Program in Elderly Male Patients of Type II Diabetes Mellitus: A Retrospective Study. International Journal of Diabetes and Endocrinology 2018; 3 (2), 2018: 29-34.

[11] Modi D, Rathod G, Delwadia K, et al. Study of significance of glycosylated hemoglobin in diabetic patient. IAIM, 2016; 3 (4): $1-10$.
[12] Buse J, Bigger J, Byington R, et al. Action to Control Cardiovascular Risk in Diabetes (ACCORD) trial: design and methods. Am J Cardiol. 2007; 99 (12A): 21i-33i.

[13] Gerstein H, Riddle M, Kendall D, et al. Glycemia treatment strategies in the Action to Control Cardiovascular Risk in Diabetes (ACCORD) trial. Am J Cardiol. 2007; 99 (12A): 34i$43 i$.

[14] Gerstein H, Miller M, Byington R, et al. Effects of intensive glucose lowering in type 2 diabetes. N Engl J Med. 2008; 358 (24): $2545-59$.

[15] Al-Goblan A, Al-Alfi M, Khan M. Mechanism linking diabetes mellitus and obesity. Diabetes Metab Syndr Obes. 2014; 7: 587-591.

[16] Alzohairy M. Therapeutics Role of Azadirachta indica (Neem) and Their Active Constituents in Diseases Prevention and Treatment. Evid Based Complement Alternat Med. 2016; 2016: 7382506 .

[17] Taylor R. Calorie restriction and reversal of type 2 diabetes. Expert Rev Endocrinol Metab. 2016 Nov; 11 (6): 521-528. 